\title{
O USO DE FERRAMENTAS DE BUSCA E ACESSO A ARTIGOS ACADÊMICOS PELOS PESQUISADORES BRASILEIROS
}

\author{
Daniel Libonati Gomes \\ Alegria Celia Benchimol \\ Thiago Henrique Bragato Barros ${ }^{* *+*}$
}

RESUMO Opresente trabalho objetivou investigar quais são os mecanismos de busca e acesso a artigos científicos mais utilizados pelos pesquisadores brasileiros, abrangendo todas as áreas. Para tanto, foi aplicada uma pesquisa descritiva com survey, com abordagem quantitativa, de modo que foi desenvolvido um questionário, o qual foi enviado a coordenações de pós-graduação de todo o país, a fim de que os estudantes (mestrandos e doutorandos) e professores (mestres e doutores) o respondessem. Os resultados mostraram que as preferências de ferramentas tendem a variar entre aquelas com mais recursos, as metabases de dados (Google Acadêmico, Portal de Periódicos CAPES etc.), e aquelas de maior simplicidade (buscadores genéricos, Sci-Hub etc.), porém as últimas se sobressaem em alguns quesitos, como no caso de busca por título do artigo. Assim, concluiu-se que, diante de tanta variedade, os pesquisadores tendem a optar por ferramentas que mais rapidamente e de modo mais prático atendam suas necessidades, com o mínimo de barreiras para se alcançar o que se deseja, mais que ainda assim sejam confiáveis e garantam a relevância da informação recuperada.

Palavras-chave: Ferramentas de busca. Artigos científicos. Bases de dados. SciHub. Comunicação científica.

\begin{abstract}
* Mestrando no Programa de Pós-Gruduação em Ciência da Informação da Universidade Federal do Pará, Brasil. Especialista em Semiótica Discursiva pela Universidade de Araraquara, Brasil. Graduado em Letras - Língua Portuguesa pela Universidade do Estado do Pará, Brasil. E-mail: daniellibonati00@hotmail.com.

** Doutora em Ciência da Informação pelo Instituto Brasileiro de Informação em Ciência e Tecnologia em convênio com a Universidade Federal do Rio de Janeiro, Brasil. Tecnologista Pleno do Museu Paraense Emílio Goeldi, Brasil. Editora associada do Boletim do Museu Paraense Emílio Goeldi, Brasil. Professora permanente do Programa de Pós-Graduação em Ciência da Informação da Universidade Federal do Pará, Brasil. E-mail: alegria.benchimol@gmail.com.

*** Doutor em Ciência da Informação pela Universidade Estadual Paulista Júlio de Mesquita Filho, Brasil. Professor da Universidade Federal do Pará, Brasil. Docente do Programa de Pós-Graduação em Ciência da Informação da Universidade Federal do Pará, Brasil. Líder do grupo de pesquisa CNPq Organização e Representação em Arquivos e Bibliotecas. Presidente da Internacional Society for Knowledge Organization- Capítulo Brasileiro (2017-2019). E-mail:thiagobarros@ufpa.br.
\end{abstract}

\section{INTRODUÇÃO}

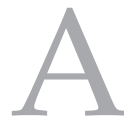

quantidade de ferramentas de busca e acesso a artigos científicos vem crescendo cada vez mais, o que tem levantado questões acerca de seu uso. Após a Segunda Guerra Mundial, especialmente durante a Guerra Fria, ocorreu a chamada "explosão informacional" (SARACEVIC, 2009), que levou a um grande aumento no número de cientistas e, consequentemente, no número de publicações e de periódicos, o que fez com que a recuperação das informações criadas fosse ficando cada vez mais difícil.

Atualmente, os pesquisadores, diante da necessidade de artigos sobre um assunto específico, possuem tantas opções de periódicos que muita informação útil acaba se perdendo. Iniciativas para realizar a classificação de periódicos com base em sua qualidade e impacto foram realizadas e auxiliam, até certo ponto, na escolha pelos melhores periódicos. No Brasil, a classificação Qualis da Coordenação de 
Aperfeiçoamento de Pessoal de Nível Superior - CAPES tem esse objetivo, classificando os periódicos através de estratos que vão de A1 (mais elevado) até C (peso zero). Contudo, a escolha de periódicos com base nos estratos pode levar a uma ocorrência de Efeito Mateus, em que os periódicos de maior estrato são cada vez mais lidos e os de menor são cada vez menos, de modo que muitos trabalhos relevantes acabam ficando sem visibilidade.

Porém, também foram desenvolvidas ferramentas para busca de artigos científicos sem a necessidade de se procurar por um periódico específico: as bases de dados. Essas são bancos de dados que indexam artigos de vários periódicos de alguma área específica ou de áreas diferentes. Além das bases de dados, há também o que se optou por chamar aqui neste trabalho de metabases de dados, que nada mais são do que bases maiores, que armazenam outras bases menores. A diferença entre bases e metabases de dados foi pensada por serem, na prática, ferramentas que são usadas por motivos diferentes apesar de terem exatamente a mesma função.

Há ainda outra barreira que se levantou na busca por artigos científicos, mesmo com o uso de bases e metabases de dados: o mercado editorial. De fato, as editoras dos periódicos necessitam de capital para realizar suas atividades, porém, para muitos pesquisadores, isso acaba sendo um grande problema, justamente por conta dos altos valores cobrados para se ter acesso aos artigos. Isso inviabiliza o trabalho de boa parte dos cientistas, que precisam de determinados trabalhos, mas desistem ao se verem diante de paywalls (páginas que mostram informações de compra da permissão para ler o artigo). Antes, nessas situações, os cientistas recorriam às bibliotecas, que assinavam as principais revistas acadêmicas a fim de disponibilizar o acesso aos pesquisadores, porém, com o número crescente de periódicos, mesmo essa alternativa tem se tornado inviável, considerando o aumento dos valores cobrados pelas editoras. A partir desse quadro, surgiram alternativas para resolver esse problema, as quais serão mais bem abordadas na seção seguinte.

Assim, diante do que foi exposto, destaca-se o objetivo do presente trabalho: investigar quais ferramentas de busca e acesso a artigos científicos são mais utilizadas pelos pesquisadores brasileiros de todas as áreas. Esse objetivo se baseia na ideia de que, diante de tantos modos de ter acesso a artigos, certamente deve haver ferramentas que se sobressaem, atraindo maior número de usuários. Logo, pode existir um motivo que leve tais ferramentas a serem preferidas, como a quantidade de recursos disponíveis, a facilidade de acesso ou mesmo a praticidade do uso. Dessa forma, nas seções a seguir será explicado mais detalhadamente acerca das bases, metabases de dados e acesso aberto a fim de esclarecer elementos pertinentes à discussão da temática da investigação proposta, para depois expor a metodologia, a discussão e os resultados da pesquisa.

\section{OS MECANISMOS DE BUSCA ACADÊMICA}

A fim de obter acesso a materiais acadêmicos de interesse, os pesquisadores recorrem, como já foi exposto, a bases e metabases de dados ou, para utilizar uma expressão mais genérica, mecanismos de busca acadêmica, expressão utilizada por Beel, Gipp e Wilde (2010) como sinônimo para bases de dados acadêmicas. Tais mecanismos de busca têm como objetivo recuperar as informações necessárias para uso na atividade científica. Segundo Buchinger, Cavalcanti e Hounsell (2014, p. 109), um mecanismo de busca "é a composição de site, motor de busca, recursos de interface e conjunto de bases de dados que cobrem uma determinada área de conhecimento, visando a facilitar a identificação de materiais específicos e relevantes", ou seja, essa expressão se refere à página da internet, com todos os seus recursos e características, que permite ao usuário ter acesso a material acadêmico.

Diante da existência de vários periódicos destinados a mesma temática, é natural que um pesquisador tenha dúvidas acerca de onde encontrar as melhores informações. Por conta disso, a existência das bases de dados é de grande importância, pois torna mais viável o trabalho de pesquisa bibliográfica ou mesmo de dados de pesquisas.

Para exemplificar o que se entende aqui por base de dados, pode-se citar o programa Scientific Electronic Library Online - SciELO, surgido em 1998 a partir de um projeto-piloto 
realizado pela Fundação de Amparo à Pesquisa do Estado de São Paulo - FAPESP em parceria com o Centro Latino-Americano e do Caribe em Informação em Ciências da Saúde - BIREME/ OPAS/OMS. Conforme explicam Packer et al. (2014, p. 17):

\begin{abstract}
O SciELO foi concebido como um projeto e uma estratégia para superar o fenômeno conhecido como "ciência perdida", causado pela presença muito fraca dos periódicos de países em desenvolvimento nos índices internacionais. Além da falta de visibilidade, este fenômeno também se manifestou na falta de comunicação, em muitas áreas, entre os pesquisadores de países desenvolvidos e em desenvolvimento, bem como entre os pesquisadores de países em desenvolvimento.
\end{abstract}

Dessa forma, é evidente que o desenvolvimento do SciELO se mostra coerente com o que foi anteriormente colocado acerca da necessidade de ferramentas de busca de artigos científicos. Sem as bases de dados, muitos artigos acabam por perder a visibilidade, o que evidentemente prejudica a ciência como um todo, pois impede que trabalhos de qualidade possam garantir sua contribuição.

No momento em que se redige este texto (30 de outubro de 2017), o SciELO possui indexados 1447 periódicos, divididos em 49910 fascículos, totalizando 713987 artigos. É atualmente uma das principais bases de dados nacionais, disponibilizando abertamente artigos de todas as áreas de conhecimento.

Porém, cabe ainda mencionar que existem bases de dados mais específicas, que atendem a apenas uma área de conhecimento. Um exemplo, na própria Ciência da Informação, é a Base de Dados em Ciência da Informação BRAPCI, que indexa atualmente 56 periódicos, disponibilizando 17637 trabalhos. Ou ainda, na medicina, pode-se citar o PubMed Central - PMC, que indexa cerca de 4,5 milhões de artigos. Outra forma de bases de dados são os repositórios, que tendem a ter conteúdo mais específico, podendo até mesmo ser limitado a uma instituição.

É importante também esclarecer acerca do que aqui foi chamado metabases de dados. As metabases seriam aquelas que indexam em si bases de dados inteiras, ou seja, possuem maior amplitude, recuperando uma quantidade maior de trabalhos de todas as áreas (ver Figura 1). Como já foi esclarecido na introdução, optou-se por diferenciar essas ferramentas das bases de dados comuns, visto que, em geral, as motivações de uso tendem a ser diferentes: para uma pesquisa mais específica, um usuário pode facilmente acessar um repositório ou uma base de dados como a BRAPCI, porém, se a busca é mais ampla, com caráter mais interdisciplinar, por exemplo, uma ferramenta como o Portal de Periódicos CAPES pode garantir melhores resultados. Acerca do termo "metabase", em uma busca realizada através do Google Acadêmico e do Portal de Periódicos CAPES pelos termos "metabases de dados", "metabases de dados acadêmicos", "metadatabase" e "academic metadatabase", não foi encontrado resultado com o mesmo sentido do aqui proposto. O termo "metabase de dados" é, geralmente, utilizado para se referir a bases de metadados, contudo, neste trabalho, optou-se pelo prefixo "meta" para indicar a ideia de transcendência, ou seja, uma metabase de dados está além de uma base de dados comum.

\section{Figura 1: Relação Periódicos $X$ Bases $X$} Metabases

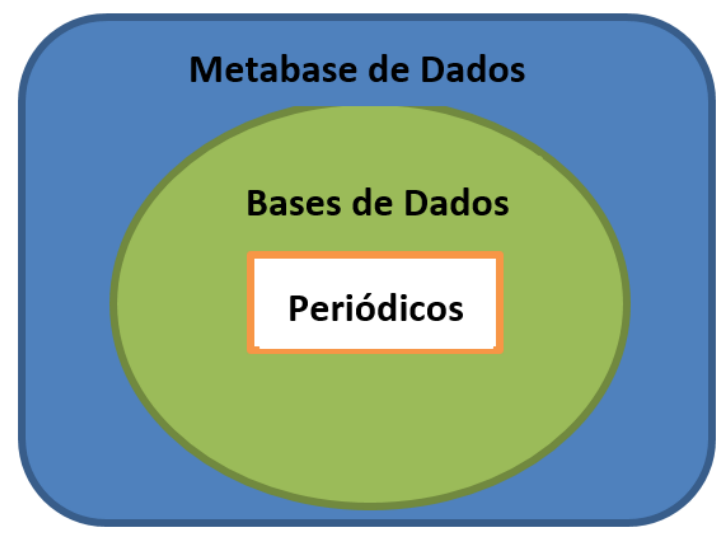

Fonte: Elaborado pelos autores, 2017

Dentre as principais metabases de dados, pode-se citar o exemplo nacional do Portal de Periódicos CAPES, criado em 2000. Sobre ele, Almeida, Guimarães e Alves (2010, p. 228) explicam que:

O Portal de Periódicos nasceu como forma de otimizar a política de acesso atualizado ao conhecimento científico. Sua implantação 
permitiu uma redução do custo médio do acesso por usuário e um direcionamento, em médio prazo, dos investimentos feitos pelo governo brasileiro por meio de uma análise precisa da utilização dos periódicos pela comunidade atendida. Ao mesmo tempo, buscou promover crescentemente $\mathrm{o}$ acesso universal a um acervo amplo e atualizado de textos completos publicados em periódicos internacionais e a bases de referência, sem limitações geográficas e de horário. Permitiu, finalmente, o preenchimento das então enormes lacunas nas coleções das bibliotecas, devido às eternas irregularidades no aporte de recursos destinados ao setor.

Dessa forma, uma ferramenta como o Portal de Periódicos CAPES consegue, dada a abrangência de seu banco de dados, composto por artigos (acadêmicos e de jornais), resenhas, atas de congresso e recursos textuais, atender a uma grande demanda, formada por pesquisadores de todo o Brasil. Porém, cabe frisar que há ainda diversas outras metabases de dados, tal como o já citado Google Acadêmico, bastante popular por conta de sua simplicidade e praticidade. As chamadas federações de repositórios, como a Biblioteca Digital Brasileira de Teses e Dissertações - BDTD e o Repositório Científico de Acesso Aberto de Portugal RCAAP, que agrupam diversos repositórios menores visando à colaboração (SHINTAKU; DUQUE; SUAIDEN, 2015), também podem ser considerados metabases de dados.

Buchinger, Cavalcanti e Hounsell (2014) investigaram algumas das principais bases e metabases de dados (sem fazer distinção) através de uma pesquisa quantitativa e concluíram que, apesar de alguns dos mecanismos de busca acadêmica serem evidentemente maiores e apresentarem mais recursos que outros (inclusive o Google Acadêmico sendo o pior no que concerne a recursos), há fatores subjetivos que levam um pesquisador a preferir uma ou outra ferramenta: usabilidade da interface e preferência do próprio cientista, baseada em sua experiência com pesquisa. Assim, é evidente que o uso de mecanismos de busca acadêmica não considera apenas questões relacionadas ao sistema em si, mas também ao usuário e suas necessidades.

Diante da necessidade de ter acesso a algum artigo sobre um determinado tema, o pesquisador certamente busca através da ferramenta que considera mais simples e prática, a qual permita que ele recupere a informação que necessita (ou ao menos aquelas informações que são relevantes) no menor tempo possível. Porém, algumas ferramentas, como o Google Acadêmico e o Scopus, podem levar o usuário a um paywall, um muro de pagamento, ou seja, uma página cujo objetivo é simplesmente mostrar os metadados do artigo desejado juntamente com informações para a compra do texto. Por conta disso, considerando que boa parte dos artigos necessários para a realização de uma pesquisa possam estar bloqueados por paywalls, muitos trabalhos são prejudicados, em escala mundial. Não é exagero afirmar que para a realização de alguns estudos pode ser necessário o pagamento de milhares de dólares em artigos científicos. É nesse ponto, portanto, que está a importância do acesso aberto (open access).

\section{AS INICIATIVAS DE ACESSO ABERTO}

Em meados da década de 1980 se iniciou a chamada crise dos periódicos, em que as bibliotecas universitárias não estavam mais conseguindo manter suas coleções de periódicos devido à crescente demanda por parte dos usuários (MUELLER, 2006). O valor cobrado pelas assinaturas, devido, dentre outros fatores, ao aumento do impacto de algumas revistas, começou a aumentar de modo a tornar inviável a aquisição de novos volumes aos acervos.

Isso aos poucos levou à discussão acerca do acesso aberto, ou seja, a disponibilização gratuita de material científico (o que inclui artigos, teses, dissertações, publicações em anais etc.) para todos aqueles interessados em utilizálo. As primeiras iniciativas de acesso aberto ocorreram ainda no início da década de 1990, com o desenvolvimento, por exemplo, do ArXiv, do Laboratório Nacional de Los Alamos, nos Estados Unidos, que permitia a pesquisadores da área da física enviarem seus trabalhos para que todos pudessem ter acesso.

Diversas iniciativas foram realizadas a fim de discutir acerca do acesso aberto. Dentre elas, pode-se citar a Budapest Open Access Iniative - BOAI, de 2002, em que foram definidas duas estratégias com base no protocolo Open Archives Initiative - Protocol for metadata 
Harvesting - OAI-PMH para tornar o acesso aberto uma realidade: a via verde (green road) e a via dourada (gold road). A via verde se refere ao auto arquivamento, ou seja, os próprios cientistas disponibilizarem a todos seus trabalhos. Repositórios institucionais são um dos melhores exemplos de realização dessa estratégia. A segunda, a via dourada, ocorre quando os próprios periódicos, como um todo, possuem acesso aberto, ou seja, o autor envia seu artigo para a edição e a revista disponibiliza o texto gratuitamente. No Brasil, a via dourada é uma realidade, visto que os principais periódicos do país possuem acesso aberto, além de que o país também é um dos maiores contribuintes do Directory of Open Access Journals - DOAJ, em termos de quantidade de artigos.

Importante citar a Reunião de Bethesda, de 2003, em que foi estabelecido o que define uma publicação de acesso aberto. Para que algo, portanto, seja considerado de acesso aberto, é necessário que duas condições sejam estabelecidas (COSTA, 2006): 1) os autores e detentores dos direitos autorais devem garantir aos usuários o direito livre, irrevogável e perpétuo de acesso aos seus trabalhos, além de licença para copiar, distribuir, usar, transmitir e exibir os trabalhos publicamente em qualquer meio e propósito responsável, desde que haja atribuição apropriada da autoria; e 2) que uma versão completa do trabalho original e do material suplementar, juntamente com uma cópia da permissão citada na primeira condição, deve ser depositada em um repositório on-line, o qual deve ser mantido por uma instituição acadêmica, sociedade científica ou agência governamental ou outra instituição bem estabelecida que se responsabilize por permitir o acesso livre, distribuição irrestrita, interoperabilidade e arquivamento a longo prazo.

Alves (2008, p. 135) também aponta a Declaração de Berlim, de 2003, chamada de Open Access to Knowledge in the Sciences and Humanities, que viu na internet uma ferramenta funcional para o compartilhamento de conhecimento científico e reflexão sobre o ser humano, além de "estabelecer medidas que precisam ser consideradas entre os formuladores de política, instituições de pesquisa, agências de fomento, bibliotecas e museus". A fim de atuar conforme a Declaração de Berlim, as instituições devem:
- implementar uma política para requerer de seus pesquisadores que depositem em um repositório de acesso aberto uma cópia de todos os seus artigos publicados; e

\begin{abstract}
- encorajar seus pesquisadores a publicar seus artigos de pesquisa em periódicos de acesso aberto - onde haja um periódico apropriado - e prover o apoio necessário para que isso aconteça). (COSTA, 2006, p.43)
\end{abstract}

Publicar em periódicos de acesso aberto, atualmente, praticamente não é mais visto com desconfiança, uma situação bem diferente de quando o movimento começou. Como aponta Harnad et al. (2008), o acesso aberto permite que mais pesquisadores tenham acesso a um determinado artigo, tornando suas chances de ser citado muito maiores. De fato, a questão financeira envolvendo suas publicações em geral não é preocupação dos cientistas, apenas das editoras. Diante da possibilidade de ser mais citado e, consequentemente, alcançar maior prestígio, os pesquisadores tendem a procurar o acesso aberto, especialmente a via dourada. Além disso, vale frisar a afirmação de Kuramoto (2006, p. 92):

É importante ressaltar que as pesquisas científicas, em sua maioria, são financiadas pelo Estado, portanto, com recursos públicos. Do ponto de vista ético, os resultados dessas pesquisas deveriam ser de livre acesso. Não é isso, entretanto, o que acontece no sistema de comunicação científica tradicional. O pesquisador ou qualquer outro cidadão, para ter acesso àquilo que foi produzido com o apoio do Estado, precisará pagar pela assinatura de uma publicação científica. Trata-se de uma situação paradoxal, pois o Estado, para promover o acesso àquilo que produz, é obrigado a arcar com os custos de manutenção das coleções das revistas em que são publicados os resultados de sua produção científica. É evidente que essas coleções disseminam também resultados de pesquisas promovidas por outros países e instituições.

Dessa forma, fica também bastante clara a contradição existente no agir do mercado editorial, o que afasta diversos pesquisadores. No entanto, algumas das mais importantes revistas 
do mundo ainda não possuem acesso aberto. Um exemplo na Ciência da Informação é o Journal of Documentation, que atualmente cobra uma taxa de $\$ 32.00$ por artigo.

Diante dessa situação, outra saída foi desenvolvida, mas dessa vez de forma ilegal. Descrita como uma "estudante de ciências frustrada" por Bohannon (2016, p. 511), Alexandra Elbakyan desenvolveu o site Sci-Hub, que permite a pesquisadores de qualquer local do mundo fazerem o download dos artigos que precisam, sejam eles pagos ou não.

\section{I SCl-HUB e o acesso aberto}

O Sci-Hub ${ }^{1}$ é uma página simples e direta: uma imagem de um corvo segurando uma chave, uma caixa de busca com os dizeres "entre URL, PMID/DOI ou search string" acompanhada de um botão escrito "abrir" (ao invés do tradicional "buscar"), além da sugestiva mensagem "SciHub... remover todas as barreiras no caminho da ciência". Ao inserir uma das informações pedidas na caixa de diálogo, o usuário é prontamente levado ao arquivo PDF do artigo solicitado. No início deste trabalho, falou-se em "ferramentas de busca e acesso a artigos científicos", essa denominação foi feita pelo fato de o Sci-Hub não ser uma ferramenta de busca (diferente dos mecanismos de busca acadêmica já discutidos), mas apenas de acesso.

A página alega ser a favor do acesso aberto, afirmando "Nos posicionamos contra o ganho injusto que as editoras conseguem ao impor barreiras à distribuição de conhecimento". Atualmente, o acervo do Sci-Hub conta com aproximadamente 64,5 milhões de artigos. Basicamente, ao inserir, por exemplo, o DOI de um artigo na caixa de diálogo e clicar em "abrir", o site procura pelo artigo solicitado em uma base de dados denominada LibGen (que oferece o mesmo serviço que o Sci-Hub) e, caso não o encontre lá, a página ainda possui uma enorme quantidade de senhas de acesso a sistemas institucionais (segundo Elbakyan (BOHANNON, 2016), oferecidas ao Sci-Hub pelos próprios

\footnotetext{
I Atualmente, o site pode ser acessado a partir dos seguintes endereços: na web comum http://sci-hub.la/; http://sci-hub.hk/; http://sci-hub. mn/; http://sci-hub.name/; http://sci-hub.tv; http://sci-hub.tw; ou ainda, através do endereço da rede Onion https://scihub22266oqcxt.onion. link/.
}

donos das senhas) que permitem que ele busque na página das próprias revistas pelo texto (SMITH, 2016).

Contudo, segundo Priego (2016), o Sci-Hub não é realmente uma plataforma de acesso aberto. Para ele, acesso aberto não é sobre quebrar regras de direitos autorais, não importando o quão problemáticas elas sejam, mas sim sobre liberar o acesso à informação em todos os seus estágios, desde a criação até a publicação. A publicação em acesso aberto é feita para ter acesso aberto, e não ser forçada a isso. Ainda, afirma:

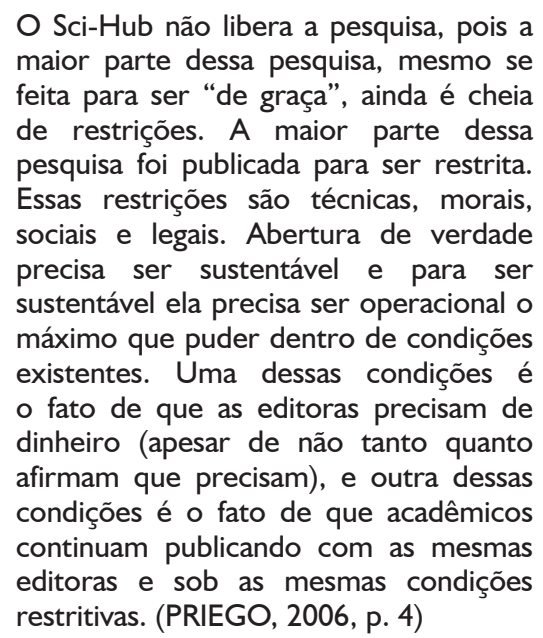

Dessa forma, esse autor faz questão de lembrar as diversas condições existentes na publicação de um artigo, considerando que, ao simplesmente liberar um artigo que deveria ser pago, restrições de diversas maneiras são quebradas, de modo que a própria imagem do movimento de acesso aberto pode ser prejudicada. Sobre isso, um dos entrevistados do trabalho de Bohannon (2016, p. 512) afirma: "Acesso aberto legalizado força as editoras a se adaptarem [...], no entanto acesso aberto ilegal, em vez disso, convida-as a processar". Também, é possível corroborar as afirmações de Priego ao relacionar a ação do Sci-Hub às definições da Reunião de Bethesda.

Ainda assim, mesmo diante desse quadro entre uma luta ideológica e a lei, pesquisadores de diversos países fazem downloads de artigos pelo Sci-Hub. Machin-Mastromatteo, UribeTirado e Romero-Ortiz (2016), ao analisar os dados de downloads do Sci-Hub dos países latino americanos num período de seis meses, 
constataram que o Brasil encabeçou a lista com o total de 1.021 .540 downloads, além do que, segundo Bohannon (2016), o país é o sexto lugar mundial em downloads - o primeiro lugar é o Irã, o segundo é a China, terceiro é a India, quarto é a Rússia e o quinto os Estados Unidos.

Diante desses dados, pode-se pensar que essas estatísticas são naturais, considerando que a demanda por artigos é grande e muitos deles são pagos. Porém, no caso do Brasil, a necessidade de pagar pelos artigos muitas vezes não existe, visto que o governo já pagou por eles: o país tem o Portal de Periódicos CAPES. Em outros países, como os próprios Estados Unidos, conseguese acesso a esses artigos pagos a partir de bibliotecas, mas ainda assim há um uso massivo do Sci-Hub.

\section{METODOLOGIA}

O presente trabalho consistiu de uma pesquisa descritiva com survey, tendo abordagem quantitativa, de modo que se procurou investigar quais são as ferramentas de busca e acesso a artigos científicos usadas pelos pesquisadores brasileiros de todas as áreas - Ciências Agrárias, Ciências Humanas, Ciências Exatas e da Terra, Ciências Sociais Aplicadas, Engenharias, Ciências da Saúde, Ciências Biológicas e Linguística, Letras e Artes. A pesquisa foi feita conforme explica Fonseca (2002, p. 33 apud SILVEIRA; CÓRDOVA, 2009, p. 39):

\begin{abstract}
A pesquisa com survey pode ser referida como sendo a obtenção de dados ou informações sobre as características ou as opiniões de determinado grupo de pessoas, indicado como representante de uma população-alvo, utilizando um questionário como instrumento de pesquisa.
\end{abstract}

A ferramenta utilizada foi um questionário feito através do Google Formulários, que permite uma grande variedade de ferramentas. No entanto, foram formuladas apenas questões objetivas, seis em que apenas uma alternativa poderia ser respondida e uma em que o entrevistado poderia assinalar quantas alternativas julgassem apropriadas.

As duas primeiras perguntas tiveram como objetivo apenas identificar o estado brasileiro que o entrevistado representava e sua área de pesquisa. A terceira e quarta perguntas objetivaram conhecer as formas como o entrevistado busca pelos artigos que necessita quando está procurando por assunto ou pelo título do texto. A quinta se destinou apenas a descobrir a familiaridade do entrevistado com o Sci-Hub e a sexta voltou-se a sabe qual ação ele toma diante de um artigo pago. Por fim, a última pergunta consistiu de frases que o entrevistado poderia assinalar caso se identificasse. Essas frases, algumas delas claramente redundantes, objetivaram traçar um perfil mais ideológico do entrevistado, seu posicionamento diante da questão do acesso aberto e da existência de paywalls.

O questionário foi enviado a coordenações de pós-graduação de universidades públicas de vários estados brasileiros, de todas as cinco regiões, via e-mail, solicitando que fosse repassado aos alunos (mestrandos e doutorandos) e professores (mestres e doutores).

A análise dos dados foi realizada a partir da organização de um banco de dados através do software Microsoft Office Excel 2010, sendo o cálculo estatístico feito a partir do software Epilnfo 3.5.2. Foi calculado o percentual de cada variável considerando o intervalo de confiança de $95 \%$.

\section{RESULTADOS E DISCUSSÃO}

O questionário enviado às coordenações de pós-graduações obteve um total de 2799 respostas, abrangendo todas as regiões do país e todas as áreas de estudo. Os gráficos 1 e 2 abaixo expõem a porcentagem a de acordo com a região e com as áreas: 
Gráfico 1: Regiões de atuação

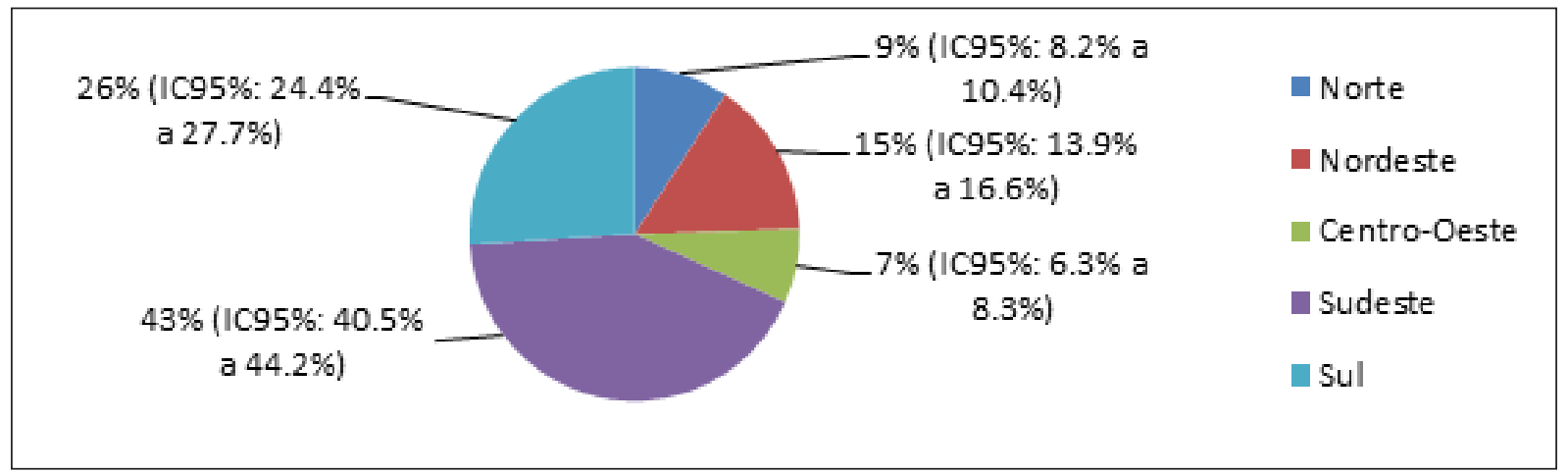

Fonte: Dados da pesquisa, 2017

Gráfico 2: Áreas de pesquisa

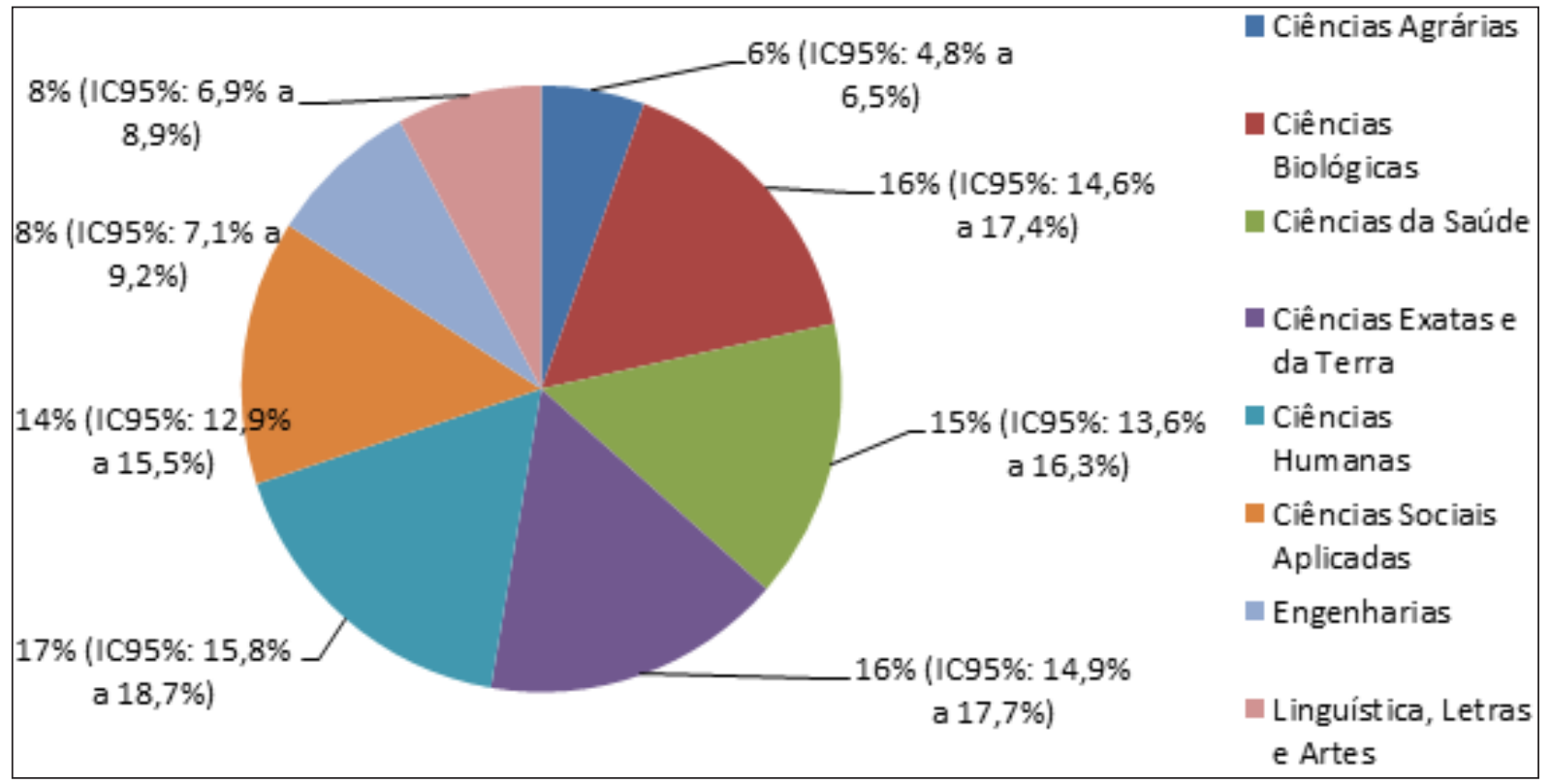

Fonte: Dados da pesquisa, 2017

Dessa forma, garantiu-se que haveria certo equilíbrio nas respostas no que concerne à região e área de pesquisa dos entrevistados. As porcentagens são próximas aos do último censo realizado pelo CNPQ (2016), que verificou a distribuição de pesquisadores pelo Brasil e concluiu que $6,3 \%$ estão no Norte; $20,5 \%$ no Nordeste, $7,7 \%$ no Centro-Oeste; $42,5 \%$ no Sudeste e 22,9\% no Sul, em um total de 199.566 pesquisadores.

Acerca das estratégias de pesquisa (ver Gráfico 3), a maioria dos entrevistados,
49\% (IC95\%: 46,8\% a 50,5\%), afirmou que, ao pesquisar artigos sobre algum assunto específico, prefere utilizar metabases de dados. Uma quantidade consideravelmente menor opta pelo buscador do Google (ou outra ferramenta equivalente, como o Bing) - 24\% (IC95\%: 22,8\% a 26\%) - ou bases de dados - 23\% (IC95\%: 21\% a $24,1 \%)$. Isso evidencia que a busca por assunto, em geral, é motivação para realizar a pesquisa em ferramentas mais abrangentes. A procura por periódicos impressos se mostrou quase nula. 
Gráfico 3: Pesquisa por assunto

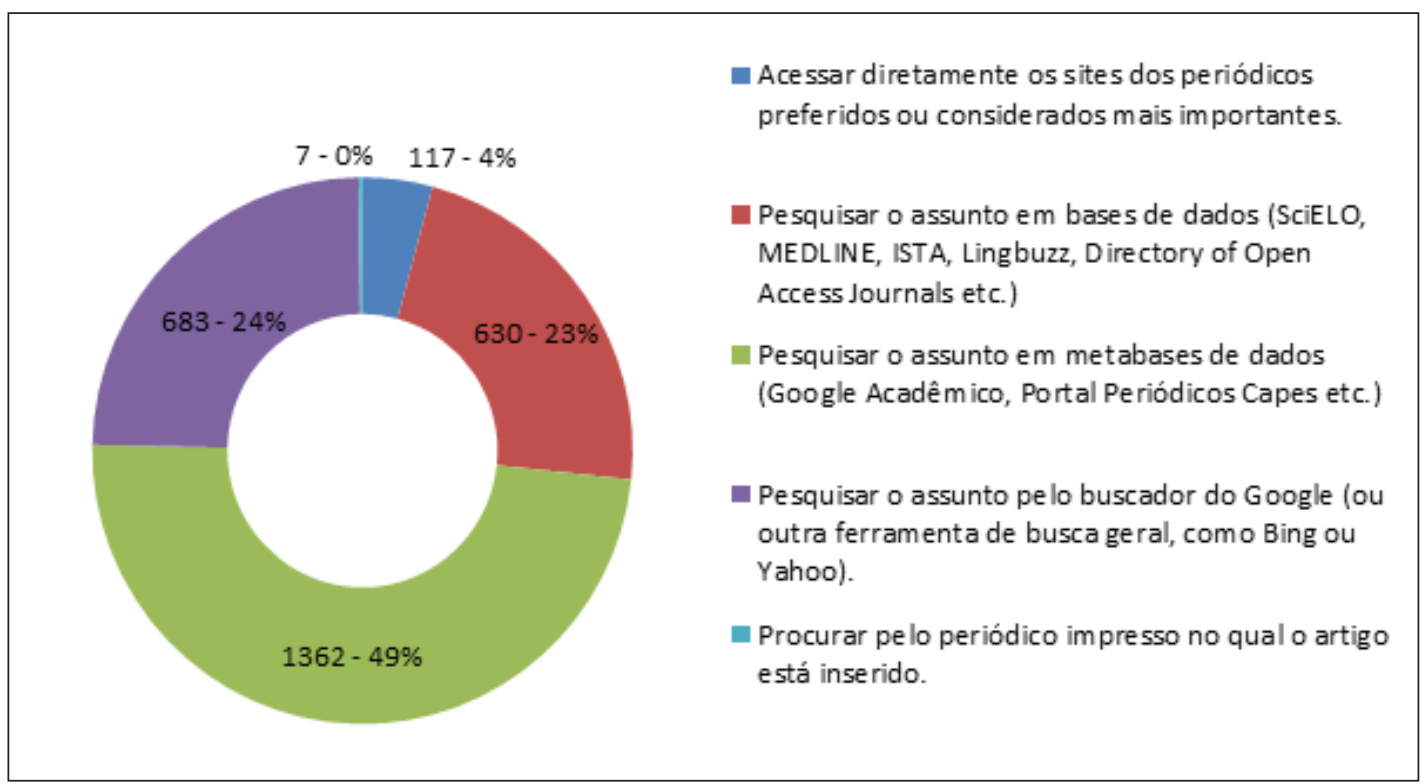

Fonte: Dados da pesquisa, 2017

No que concerne à pesquisa por um artigo específico (ver Gráfico 4), ou seja, pelo título, a maioria dos entrevistados (39\%, IC95\%: 36,8\% a $40,4 \%)$ prefere, de modo bastante contrário à pesquisa por assunto, buscar pelo título do artigo no próprio buscador do Google. Porém, há ainda uma boa parte (36\%, IC95\%: 34,6\% a $38,2 \%)$ que utiliza as metabases de dados para esse tipo de busca. Da mesma forma que os resultados anteriores da pesquisa por assunto, uma menor parta utiliza as bases de dados - 16\% (IC95\%: 15\% a 17,8\%) -, havendo ainda aqueles que acessam diretamente a página do periódico que indexa o artigo desejado - 8\% (IC95\%: 7,2\% a $9,2 \%$ ). Também aqui, a procura por periódicos impressos foi mínima.

Gráfico 4: Pesquisa por título

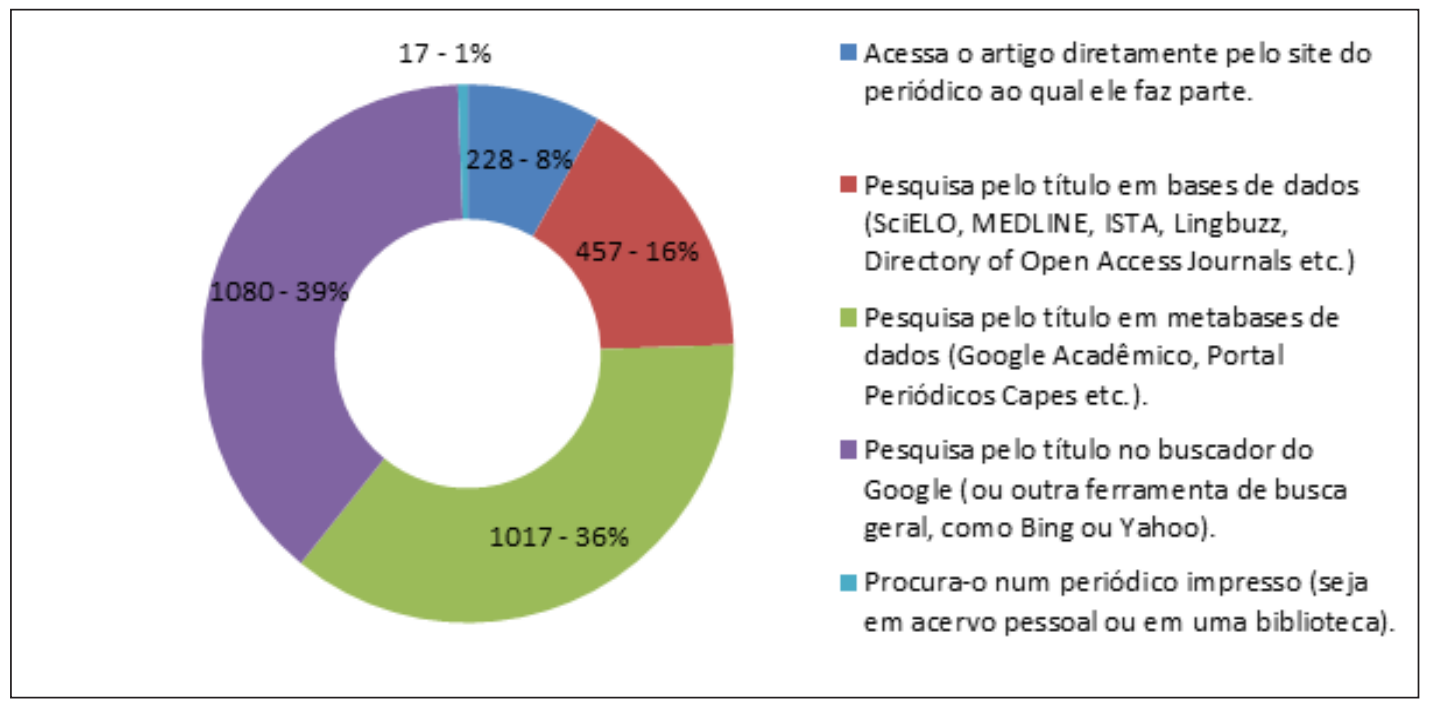

Fonte: Dados da pesquisa, 2017

Inf. \& Soc.:Est., João Pessoa, v.28, n.1, p. 141-154, jan./abr. 2018 
Conforme dito na seção anterior, houve uma questão com o intuito de unicamente conhecer a familiaridade dos entrevistados com o Sci-Hub (ver Gráfico 5). A maioria (41\%, IC95\%: $39,9 \%$ a $43,1 \%$ ) mostrou desconhecimento total da ferramenta, porém uma boa parcela o usa constantemente $(25 \%$, IC95\%: $23,5 \%$ a $26,7 \%$ ) ou já usou pelo menos algumas vezes (17\%, IC95\%: 15,9\% a 18,7\%), de modo que é possível afirmar que ao menos $42 \%$ dos entrevistados já teve algum contato com o site. Em menor quantidade, há entrevistados que mostraram conhecerem a página pelo nome, mas nunca terem utilizado (12\%, IC95\%: $10,3 \%$ a $12,7 \%$ ) e outros que indicaram a mesma alternativa, porém destacando que não veem problemas em utilizar a ferramenta (4\%, IC95\%: $3,4 \%$ a $4,9 \%$ ). Uma minoria afirmou conhecer a página, mas se recusar a utilizá-la (1\%, IC95\%: $0,6 \%$ a $1,3 \%)$.

Gráfico 5: Familiaridade com o Sci-Hub

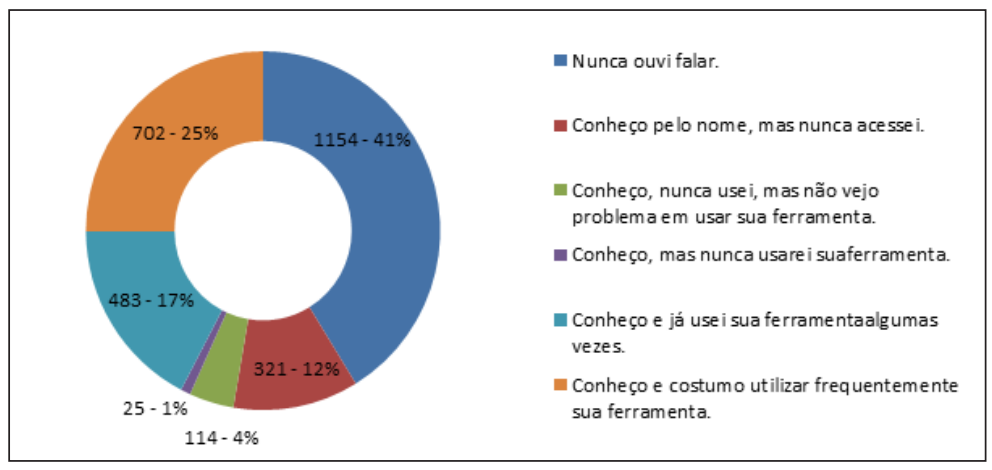

Fonte: Dados da pesquisa, 2017

Com base nesses resultados, é possível compreender melhor a ação dos entrevistados diante de paywalls (ver Gráfico 6). A maior parte (44\%, IC95\%: $42,8 \%$ a $46,5 \%$ ) afirmou utilizar o Portal de Periódicos CAPES quando precisa de um artigo que é pago, enquanto que $33 \%$ (IC95\%: 31,2\% a 34,7\%) optam pelo Sci-Hub, o que pode sugerir que parte dos indivíduos que tem conhecimento da ferramenta ainda possui receio de usá-la ou prefere o Portal de Periódicos pelo fato de também ser uma ferramenta de busca, o que é claramente um recurso a mais. Além disso, os periódicos impressos parecem ter um impacto maior nos casos de artigos pagos, considerando que $12 \%$ (IC95\%: $10,6 \%$ a $13 \%$ ) dos entrevistados os procura em alguma biblioteca. Uma quantidade próxima, 9\% (IC95\%: 8\% a $10,2 \%$ ), prefere entrar em contato com o autor do artigo desejado e solicitar o envio de uma cópia. Apenas 2\% (IC95\%: 1,2\% a 2,2\%) optam por pagar o que for necessário.

Gráfico 6: Ação diante de paywall

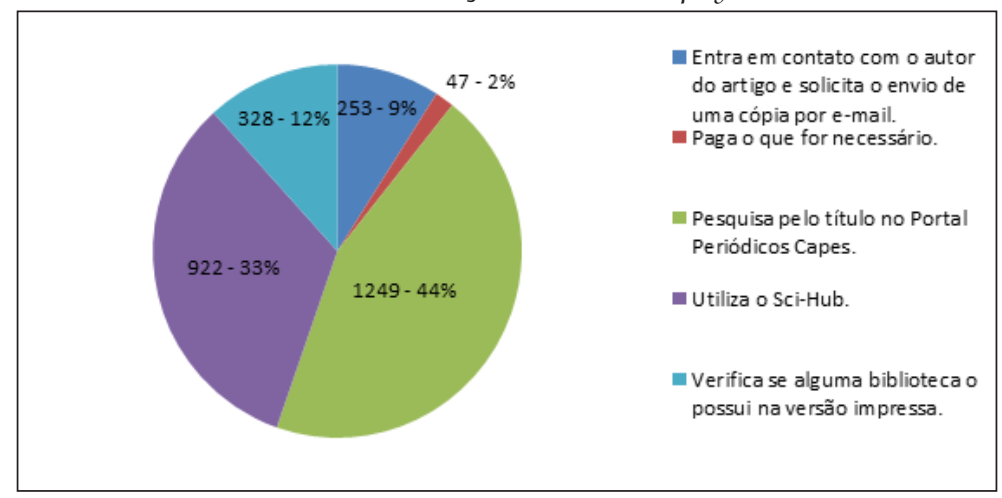

Fonte: Dados da pesquisa, 2017 
Dessa forma, a fim de se ter uma compreensão mais profunda dos entrevistados, a última questão foi realizada. O posicionamento ideológico do indivíduo pode indicar algumas das ações adotadas, e isso foi confirmado, conforme pode ser visto no Gráfico 7:

Gráfico 7: Posicionamentos diversos acerca de acesso aberto e participação na ciência

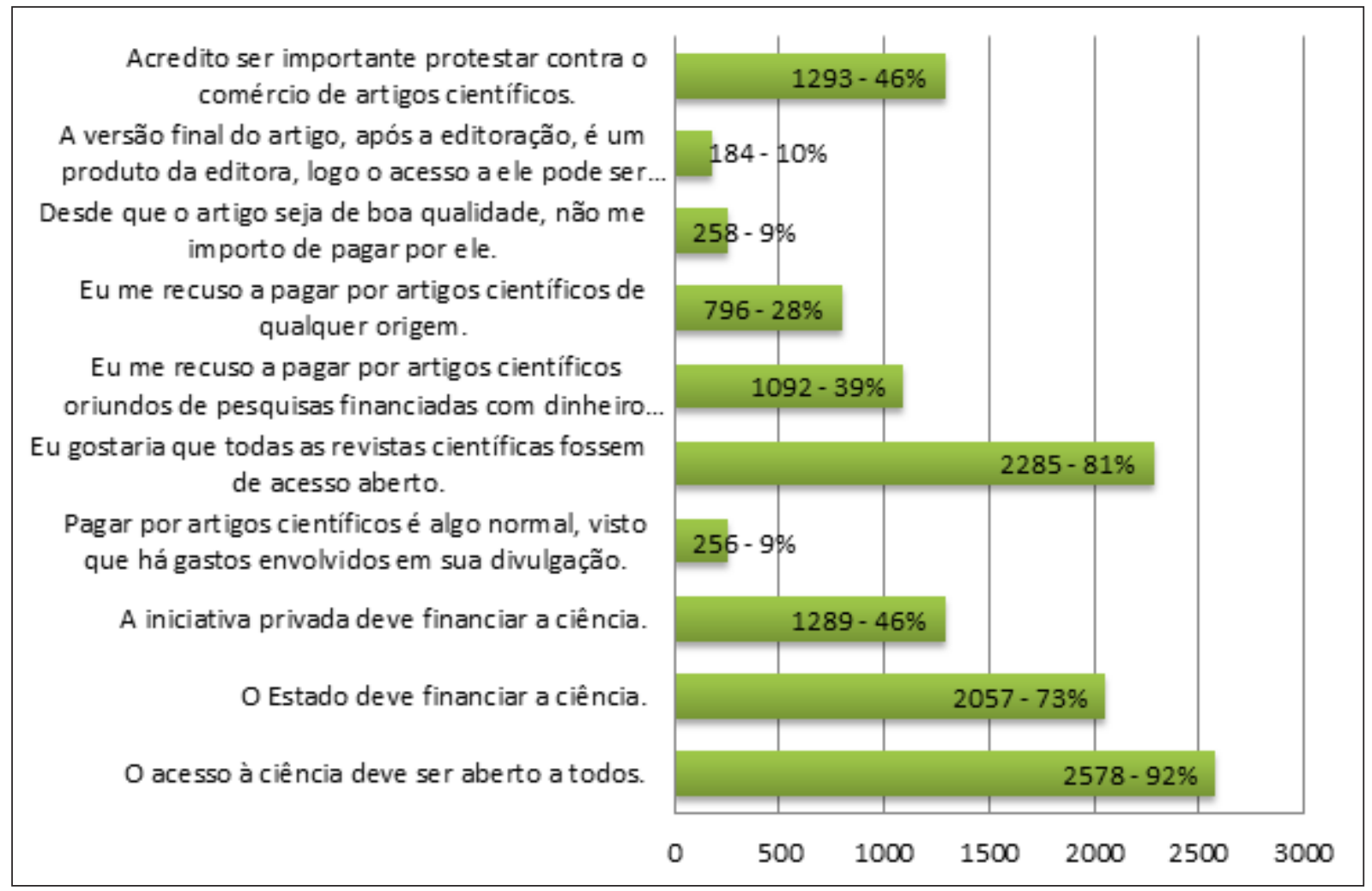

Fonte: Dados da pesquisa, 2017

Quase todos os entrevistados (92\%) afirmaram que o acesso à ciência deve ser aberto a todos, enquanto que $81 \%$ afirmaram que gostariam que todas as revistas fossem de acesso aberto. Seguindo ainda essa linha de pensamento, é possível verificar que 39\% se recusa a pagar por artigos de pesquisas realizadas com dinheiro público e $28 \%$ se recusa a pagar por qualquer artigo, além de que $73 \%$ acredita que o Estado deveria financiar a ciência, o que indica que, para alguns, uma pesquisa ser financiada pelo governo não implica necessariamente que a população não tenha que pagar para ter acesso a ela - mantendo o paradoxo mencionado por Kuramoto (2006).

Em uma perspectiva diferente, verifica-se que uma porcentagem menor dos entrevistados possui uma visão mais mercadológica da produção científica, visto que $10 \%$ vê os artigos como um produto da editora, com alguns, 9\%, considerando ainda os gastos envolvidos no processo editorial. Há também $9 \%$ que não vê problemas em pagar por um artigo desde que se saiba de sua qualidade, considerando que, em geral, o paywall somente mostra o resumo do texto, de maneira que é possível se deparar com algo que não atenda realmente as necessidades do pesquisador após a compra.

Por fim, num posicionamento que pode abarcar indivíduos com as duas perspectivas apresentadas anteriormente, $46 \%$ dos entrevistados acreditam que a iniciativa privada também deveria ter um papel de importância no financiamento da ciência. Contudo, nesse caso, os artigos certamente tenderiam a, de fato, serem compreendidos como produtos, além 
de que se devem considerar ainda os objetivos das empresas financiadoras. Além disso, vale mencionar também que $46 \%$ afirmaram acreditar que é importante protestar contra o comércio de artigos científicos, de modo que se pode considerar que, caso alguns desses $46 \%$ seja parte dos outros $46 \%$ que acredita ser importante a participação da iniciativa privada, é possível depreender uma das alternativas: caem em uma contradição; não refletiram tanto sobre o assunto; acreditam que a iniciativa privada possa contribuir com a ciência sem interesses ou que seus interesses se alinhem com os da comunidade.

Relacionando os resultados da última pergunta às anteriores, é possível perceber que, de fato, a maior parte dos pesquisadores do país evita pagar por artigos científicos, especialmente por questões ideológicas, como o pensamento de que a ciência deve beneficiar a todos, tendo os resultados alcançados pelas pesquisas também disponíveis a quem precisar.

Contudo, ainda resta a questão dos mecanismos de busca acadêmica mais utilizados. Como fica bastante claro com os resultados, as metabases de dados são uma das principais opções para busca, tanto em pesquisas por assunto quanto por artigos específicos, provavelmente graças a sua confiabilidade e tamanho de acervo. Porém, no caso dos artigos específicos, a ferramenta mais usada são os buscadores genéricos, como o Google ou Yahoo. Acredita-se que a causa disso seja a simplicidade e praticidade do uso desses buscadores. A interface de suas páginas é limpa, com caráter objetivo, diferente de algumas das principais metabases de dados, como o Portal de Periódicos CAPES, que dá diversas opções ao usuário e possui uma interface com grande quantidade de conteúdo.

No caso dos paywalls, a situação é análoga. Apesar de a maior parte dos pesquisadores optarem pelo Portal de Periódicos, há muitos que preferem utilizar o Sci-Hub, mesmo considerando sua ilegalidade. Poderia ser possível afirmar que isso se deve a uma questão cultural brasileira, porém essa não é uma justificativa cabível, visto que cientistas do mundo inteiro, muitos em países desenvolvidos, utilizam a ferramenta. Dessa forma, acredita-se que a principal causa disso seja, mais uma vez, a praticidade e objetividade que o Sci-Hub oferece, bastante diferente da página inicial do Portal de Periódicos - em que o pesquisador, para ter acesso a todo o conteúdo da metabase, precisa estar ou em uma biblioteca ou acessar utilizando um e-mail e senha institucionais. Portanto, é lícito dizer que quanto mais barreiras na utilização, quanto mais complexa for a página, mais os usuários tendem a procurar outras alternativas.

\section{CONSIDERAÇÕES FINAIS}

No Brasil, diante da grande quantidade de mecanismos de busca acadêmica, os usuários tendem a buscar aquelas que conseguem atender o mais prontamente possível suas necessidades. Por mais que haja ferramentas legalizadas e claramente eficientes, outras opções tenderão a ser consideradas, tanto por conta de seus recursos quanto por conta de sua simplicidade. Entre buscar pelo artigo desejado através do Portal de Periódicos CAPES (tendo que primeiro entrar com e-mail e senha) e consegui-lo através do Sci-Hub apenas inserindo o DOI do texto no site, boa parte dos pesquisadores opta pela segunda opção, mesmo que seja ilegal. Há um fator ideológico forte que permeia essa ação, assim como também há na recusa em usar a página de Elbakyan.

De todo modo, este estudo concluiu que, diante das opções de pesquisa dispostas aos cientistas brasileiros, estes tendem a utilizar aquelas que se mostram mais viáveis e que podem simplificar seu trabalho. Acredita-se que esse comportamento não seja exclusividade do Brasil, mas ainda é necessário desenvolver uma pesquisa para que se verifique isso. Outra proposta de pesquisa também é a verificação de quais metabases de dados são as mais utilizadas para pesquisas gerais por assunto, considerando que, pelos resultados aqui obtidos, o Google Acadêmico poderia ser um forte rival para o Portal de Periódicos ou outras metabases, justamente por conta de sua simplicidade (e apesar de sua carência de recursos).

Com base nos resultados aqui encontrados, acredita-se que o desenvolvimento de novos mecanismos de busca acadêmica (ou mesmo a reformulação dos existentes) possa ser realizado de modo a se focar tanto na questão dos recursos da ferramenta quanto, e talvez principalmente, na interface amigável e limpa, visando a garantir melhor desempenho e usabilidade da ferramenta. 
Artigo recebido em 02/02/20I 7 e aceito para publicação em 0I/03/20I8

\title{
THE USE OF SEARCH AND ACCESS MECHANISMS TO SCIENTIFIC ARTICLES BY BRAZILIAN RESEARCHERS
}

\begin{abstract}
The present work aimed to investigate the search and access mechanisms to scientific articles most used by Brazilian researchers, covering all areas. In order to do so, a descriptive research was applied with a quantitative approach. A questionnaire was developed, which was sent to postgraduate coordinations throughout the country, so that graduate students and professors could answer it. The results showed that tool preferences tend to vary between those with more resources, the metadatabases (Google Scholar, CAPES Newspaper Portal, etc.), and those of more simplicity (generic search engines, Sci-Hub etc.), but the latter stand out in some aspects, as in the case of search by title of the article. Thus, it was concluded that, given such variety of tools, researchers tend to opt for tools that more quickly and more practically meet their needs, with the minimum of barriers to achieve what is desired, but are still reliable and ensure the relevance of the information retrieved.
\end{abstract}

Keywords: $\quad$ Search engines. Scientific articles. Academic databases. Sci-Hub. Scientific communication.

\section{REFERÊNCIAS}

ALMEIDA, E. C. E.; GUIMARÃES, J. A.; ALVES, I. T. G. Dez anos do Portal de Periódicos da Capes: histórico, evolução e utilização. In: Revista Brasileira de Pós-Graduação, Brasília, v. 7, n. 13, p. 218-246, 2010.

ALVES, V. B. A. Open Archives: via verde ou via dourada? In: PontodeAcesso, Salvador, v. 2, n. 2, p. 127-137, 2008.

BEEL, J.; GIPP, B.; WILDE, E. Academic Search Engine Optimization (ASEO): Optimizing Scholarly Literature for Google Scholar \& Co. In: Journal of Scholarly Publishing, v. 41, n. 2, p. 176-190, 2010.

BENCHIMOL, A.; ARRUDA, M. I. M.; SILVA, T. C. Boletim do Museu Paraense Emílio Goeldi: do impresso ao eletrônico. In: Informação e Sociedade: estudos, João Pessoa, v. 26, n. 3, p. 8193, 2016.

BOHANNON, J. Who's Downloading Pirated Papers? Everyone. In: Sciene Magazine, v. 352, n. 6285, p. 508-512, 2016.

BUCHINGER, D.; CAVALCANTI, G. A. S.; HOUNSELL, M. S. Mecanismos de Busca Acadêmica: uma análise quantitativa. In: Revista
Brasileira de Computação Aplicada, Passo Fundo, v. 6, n. 1, p. 108-120, 2014.

BRASIL. Conselho Nacional de Desenvolvimento Científico e Tecnológico. Censo atual. Brasília, 2016. Disponível em: <http:/ / lattes.cnpq.br/web/ dgp/censo-atual/>. Acesso em: 06 de nov. 2017.

COSTA, S. M. S. Filosofia aberta, modelos de negócios e agências de fomento: elementos essenciais a uma discussão sobre o acesso aberto à informação científica. In: Ciência da Informação, Brasília, v. 35, n. 2, p. 39-50, 2006.

GASPAROTTO, M. Projetistas de interface para internet: a navegação nas mãos do usuário e a importância dos conceitos de Usabilidade e Arquitetura da Informação. In: Comunicação e Informação, São Caetano do Sul, v. 8, n. 15, p. 6870, 2007.

HARNAD, S.; BRODY, T.;VALLIÈRES, F.; CARR, L.; HITCHCOCK, S.; GINGRAS, Y.; OPPENHEIM, C.; HAJJEM, C.; HILF, E. R. The Access/Impact Problem and the Green and Gold Roads to Open Access: an update. In: Serials Review, v. 34, n. 1, p. 36-40, 2008.

KURAMOTO, H. Informação científica: proposta de um novo modelo para o Brasil. In: Ciência da Informação, Brasília, v. 35, n. 2, p. 91-102, 2006. 
MACHIN-MASTROMATTEO, J. D.; URIBETIRADO, A.; ROMERO-ORTIZ, M. E. Piracy of Scientific Papers in Latin America: an analisys os Sci-Hub usage data. In: Information Development, v. 32, n. 5, p. 1806-1814, 2016.

MUELLE, S. P. M. A comunicação científica e o movimento de acesso livre ao conhecimento. In: Ciência da Informação, Brasília, v. 35, n. 2, p. 27$38,2006$.

OLIVEIRA, E. B. P. M. Periódicos Científicos Eletrônicos: definições e histórico. In: Informação e Sociedade: estudos, João Pessoa, v. 18, n. 2, p. 69-77, 2008.

PACKER, A. L.; COP, N.; LUCCISANO, A.; RAMALHO, A.; SPINAK, E. (orgs.). SciELO 15 Anos de Acesso Aberto: um estudo analítico sobre Acesso Aberto e comunicação científica. Paris: UNESCO, 2014.

PINHEIRO, L. V. R. Do acesso livre à ciência aberta: conceitos e implicações na comunidade científica. In: Revista Eletrônica de Comunicação Informação \& Inovação em Saúde, v. 8, n. 2, p. 153-165, 2014.
PRIEGO, E. Signal, not Solution: notes on why Sci-Hub is not opening access. In: The Winnower, n. 3, 2016.

SARACEVIC, T. Information science. BATES, M.; MAACK, M. N. (Eds.) Encyclopedia of Library and Information Sciences, Nova York: Taylor \& Francis, p. 2570-2586, 2009.

SENA, N. K. Open Archives: caminho alternativo para a comunicação científica. In: Ciência da Informação, Brasília, v. 29, n. 3, p. 71-78, 2000.

SHINTAKU, M.; DUQUE, C. G.; SUAIDEN, E. J. Federações de repositórios: conceitos, políticas, características e tendências. In: Perspectivas em Ciência da Informação, v. 20, n. 3, p. 51-66, 2015.

SILVEIRA, D. T.; CÓRDOVA, F. P. A pesquisa científica. In: GERHARDT, T. E.; SILVEIRA, D. T. (org.) Métodos de Pesquisa. Porto Alegre: Editora da UFRGS, p. 31-42, 2009.

SMITH, D. Sci-Hub: how does it work? Fev. de 2016. Disponível em: < https://scholarlykitchen. sspnet.org/2016/02/25/sci-hub-how-does-itwork/> Acesso em: 06 de nov. 2017. 